\title{
Performance-based management and quality of work: an empirical assessment
}

\author{
Pierre Falzon*1 ${ }^{1}$, Adelaide Nascimento*, Corinne Gaudart**, Cécile Piney*, Marie-Anne Dujarier**, \\ Jean-François Germe*** \\ * Research Center on Work and Development, Conservatoire national des arts et métiers, Paris, France \\ ** Interdisciplinary Laboratory of Economical Sociology, Conservatoire national des arts et métiers, Paris, \\ France \\ *** Conservatoire National des Arts et Métiers, Paris, France
}

\begin{abstract}
In France, in the private sector as in the public sector, performance-based management tends to become a norm. Performance-based management is supposed to improve service quality, productivity and efficiency, transparency of allotted means and achieved results, and to better focus the activity of employees and of the whole organization. This text reports a study conducted for the French Ministry of Budget by a team of researchers in ergonomics, sociology and management science, in order to assess the impact of performance-based management on employees, on teams and on work organization. About 100 interviews were conducted with employees of all categories and 6 working groups were set up in order to discuss and validate or amend our first analyses. Results concern several aspects: workload and work intensification, indicators and performance management and the transformation of jobs induced by performance management.
\end{abstract}

Keywords: Quality of work, system ergonomics

\section{Organization management in a French public administration}

In France, in the private sector as in the public sector, performance-based management tends to become a norm. Performance is measured via indicators measuring the results of actions. The basic assumption is that these indicators allow one to measure the size and the quality of the results and to assess work efficiency by relating resources to results. Performance-based management is supposed to improve service quality, productivity and efficiency, transparency of allotted means and achieved results, and to better focus the activity of employees and of the whole organization.

Since 2001, performance-based management has been gradually implemented in all French public administrations. A specific law (the "LOLF") has been passed in order to systematically apply this mode of management. The budget presented to the Parliament is organized in programs, in missions and in actions. These are then transformed into goals, and the achievement of goals is assessed through the use of indicators.

At the same time, in order to reduce public deficits, a cost-cutting rule has been introduced in several administrations, and notably in the Ministry of Budget, where this research was conducted. Every year, only one-half of the jobs left by retiring employees is preserved. As a consequence, the performance that is sought every year -that is continually increasing- is to be achieved with a number of employees that is continually decreasing. It is to be noted that the two processes are independent: whatever the actual level of performance, high or low, the cost-cutting rule applies. Thus, the whole system operates with a will to simultaneously improve efficacy (through

${ }^{1}$ Corresponding author. Email: pierre.falzon@cnam.fr 
performance-based management) and efficiency (fulfilling goals with less personnel).

This context has led to some worries in the Ministry of Budget, which has issued a call for tenders to investigate the effect of performancebased management on the "conditions of life at work ».

This text reports the study that was then conducted for the Ministry, but independently from it, by a team of researchers in ergonomics, sociology and management science. The goal of the study was: (1) to evaluate how employees (and their hierarchy) understood performance-based management and the indicators; (2) to study the factors which can result in a degradation of the conditions of life at work; (3) to assess the impact of performance-based management on employees, on teams and on work organization.

This text will successively present some considerations on the concept of "conditions of life at work", some hypotheses and questions on the possible consequences of performance-based management on work and a summary of empirical methods. It will then highlight some of the empirical results.

\section{Conditions of life at work, work quality and quality of life}

The concept of "condition (or quality) of life at work" tends to replace the traditional idea of "work conditions". This trend has two major causes:

- Work conditions are often understood as dealing only with physical conditions: heat and cold, light, noise, vibration; task repetitiveness; manual handling; exposure to toxic products or to risks, etc. These physical difficulties are absent in a number of work situations (i.e. administration or services), which of course does not mean that work conditions are harmless in these contexts;

- Some sources of difficulties have appeared which are related more to the mental domain (psycho-social risks, stress, burn-out, karoshi). This has led to enlarge the analysis (from the work station to the global work system) and to pay a closer attention to organizational dimensions, to the content of the work and to its subjective meaning.

There is no universally agreed definition of this new concept. The French "National agency for the improvement of work conditions" [1] has proposed to define "quality of life at work[1] through a list of dimensions (translated by us):

- the quality of social relations and of work relations: work recognition, respect and attention to personnel, information, social dialogue and participation to decisions;

- the quality of work content: autonomy, variety of tasks, level of responsibility

- the quality of the physical environment: safety and physical dimensions of the ork environment

- the quality of work organization: quality of task prescription, ability of the organization to help tackling malfunctions, continuous will for progress, reduction of hard work, anticipation of work load...

- the opportunities for professional development and self-fulfillment: training, experience-based learning, competence

- the conciliation between professional and personal lives: rhythms and work hours, access to services, transportation and kindergarten.

The Anact adds that the effect of an action on each of these dimensions is not purely additive: the goal should be a global effort towards the quality of life at work.

This enlarged perspective is also at the heart of the will to re-think the indicators of economic and social progress, GDP appearing as an unsatisfying indicator. In their report, Stiglitz, Sen and Fitoussi identify and discuss new ways for measuring "quality of life" [5]. Simultaneously, attempts a redefining the "quality of work" have been undertaken by different international bodies (the "decent work" initiative of the ILO can be considered as an early attempt). The European Commission is working on the subject, via its Employment Committee (EMCO). EMCO's report on quality in work [3] emphasizes 5 dimensions: skills, lifelong learning and career development; health and safety at work; work organization and work-life balance; adequate earnings; flexibility and security.

\section{Hypotheses}

Two notions are central in the call for bids of the management of the Ministry: indicators and performance.

As concerns indicators, the call for tenders mentions that "performance-based management contributes to providing meaning to the activity of services and of employees". This can be debated. 
Performance-based management certainly orients the activity of services and of employees. In particular, indicators focus the attention on some aspects of the task and neglect others. The issue is then the acceptability of this orientation from the employees' points of view. How are indicators understood? Do they help or constrain their activities? Are they accepted, fought against, distorted? Do indicators accurately assess performance?

As concerns performance, the issue is the relation between performance as seen by the indicators (and by the Ministry?) and performance as seen by the employees. In our view, performance is a dimension of work quality for the employees also. But this quality depends on the actual possibility for the employees to obtain a satisfying performance. This in turn depends on:

- the gap between performance for the organization and performance for the employees: are they equivalent?

- the resources available to the employees: coherence between goals, quality of the procedures and processes efficiency of electronic tools, existence and relevance of training programs, work organization, autonomy and cooperation between employees and their hierarchy.

Our hypothesis is that the quality of life at work, beyond working conditions, depends on the actual possibility to produce quality at work. The concept of "quality of work" must include the subjective value of work (i.e. how work is experienced, how satisfying it is to the person) and the subjective value of its product (i.e. the quality of its results). The two are inter-related.

\section{Methodology}

The study had two main objectives: (1) to identify the way the employees understand the indicators themselves: adequacy, acceptability, positive and negative effects on the individual and team work; and (2) to analyze the relation between performance as implicitly prescribed by indicators and performance as it is self-prescribed by employees: mismatches between representations of performance, differences between resources deemed necessary and actually available resources, etc.

A two-step participative methodology was used. In a first step, qualitative field studies were conducted in 8 structures representing the variety of tasks within the Ministry, in different regions. Particular attention was paid to interactions with the public and to the role of managers. In all 100 interviews were conducted with employees of all categories. All interviews were transcribed and analyzed.

In the second step, 6 working groups were set up in order to discuss and validate or amend our first analyses. These groups included top managers and managers at the local level. Discussions focused on performance management, the way it was performed and its consequences. The goal was to propose operational changes to management.

\section{Results}

Results concern several aspects: workload and work intensification, indicators and performance management and the transformation of jobs induced by performance management.

Work intensification appears a major element of context. The feeling of intensification has several origins: constant reorganizations and implementation of new (and often bugged) tools, increased performance requirements, reduction of personnel, added tasks, "procedural bombing" leading to cognitive overload. All this leads to a transformation of activities -some tasks can no longer be performed- and to the frequently expressed opinion that the quality of produced work decreases.

The necessity of using indicators is not disputed, but several criticisms are expressed: some indicators contradict others, others do not really measure the quality of what has been done (the indicator may be good while work has been poorly done) and, most of all, indicators do not measure the actual work: some important tasks become invisible, since they are not assessed by an indicator. For instance, interactions with "users" (citizens in this case) are assessed only quantitatively, not qualitatively.

Even though managers indicate that indicators are a management tool to be used only by them, employees report that they receive instructions directly related to the fulfillment of indicators. Managers report the same situation: quantitative results become a focal point in their dialogue with their own hierarchy. According to them, goals and overall mission are forgotten; qualitative objectives are little considered; the expression of concrete difficulties and the discussion of the relation 
between resources and indicators seem difficult or impossible.

Globally, the use of indicators and of performance management, combined to the intensification of work, transforms the work of the employees and of the managers. On the managers' side, the will of their hierarchy to fulfill performance indicators leads to controversial practices of task prioritizing: tasks are not completed according to their importance in terms of the global mission, but according to their role in satisfying performance indicators. Example 1 illustrates this tendency.

The employees emphasize practices of manipulation (they say "cheating") requested by their hierarchy in order to reach the performance level as measured by indicators. It is difficult to assess the effect of these practices on the value of indicators, but they seem to affect many indicators: many examples have been reported. These practices induce a feeling of illegitimate transformation of their job. The rules of the trade are no longer respected.

\section{Example 1}

A manager explains that he prints every week a listing of late taxpayers, to whom letters should be sent. He distinguishes 3 situations: situations A where a letter should already have been sent (the indicator can no longer be satisfied), situations B where a letter should be immediately sent in order to satisfy the indicator, situations $\mathrm{C}$ where time is still available. The listing is provided to the employees, with instructions to focus on situations B.

Employees consider that this is a typical distortion of their work: situations A should be given priority, in order to fulfill their mission. Managers think differently. In their view, situations that still allow the indicator to be satisfied are to be treated first.

Simultaneously- and partly for the above reason - the job changes. Employees have no time to closely analyze files and see this as a degradation of their job and as a bad service to the public. Indicators play a negative role in that regard: they value some activities and neglect others, which may be valued by the employees (e.g. interactions with the public). In that sense, indicators shape the job in a specific, undesired way.

Reactions to this feeling of trade deterioration vary. They may lead to the individual implementation of counter-rules allowing one (in their view) to maintain a desired quality of service (cf. example 2). More generally, employees feel they achieve a lesser quality in fulfilling their mission: the search of performance comes first, a just application of the rules comes only second. This will be developed below.

\section{Example 2}

In one of the investigated structures, the management requests employees not to send request for income tax return to individuals who are not taxable due to a probably too low income. One of the employees disagrees with this policy. She thinks that declaring one's revenue is a duty for all citizens, which additionally allows one to receive a certificate of tax exemption (such a certificate may be needed for obtaining some allowances). In her view, sending a request to late individuals is thus both a civic and social act. Not doing it is not acting in a just way. This employee declares: "I have to hide what I do. For instance, I click in order to send a letter to the taxpayer, although I should not do it) and then I de-click, so that it cannot be seen. Thus I lose time in order to work in an appropriate way. [...] I do not know how to do to work in another way."

\section{Interpretation models}

Two models can be put forward to interpret these results: Boltanski's and Thevenot's theory of justice, Rasmssen's model of migrations.

\subsection{Work and justice}

Boltanski and Thevenot [2] emphasize that employees give a great importance to principles of justice. Their reactions to situations and to changes (in salary, in personnel, in work organizations) strongly depend on an assessment of justice and fairness regarding the decisions that affect them. This assessment is a key element in their opinion on the quality of their job. It extends to the treatment of the users of a service: are they treated in a fair and just way? In this perspective, performing a quality job is treating users in a just way. This assessment is of course very important in a public service and contributes to a large extent to the motivation of the employees.

In any organization, multiple logics are at work. These logics may be contradictory and give rise to disagreements and debates, based on differing 
criteria. Each of these logics proposes a specific vision of what is appropriate, just and fair.

As a matter of fact, the evolutions of the work in the organization understudy are often felt as negative: their consequence is an unfair treatment of the users, to the sole benefit of a short-sighted view of performance. Being effective and efficient is not refused as such: employees understand that reducing the cost of levying taxes is also a just objective. It is refused because it is associated (maybe wrongly) with an unjust treatment of the taxpayers. The necessary balance between competing goals is unsatisfying.

Debates about justice should not be underestimated. Employees' reluctance regarding work transformations should not be understood as resistances to change. They result from a lack of explanation, a lack of debate regarding the evolution of principles of justice (and of necessary trade-offs between competing principles). In terms of action, it means that the Ministry should clarify the motivations of the reorganization in terms of justice and organize discussions about the potential contradictions between work logics.

\subsection{Migrations}

The migration model has been proposed by Rasmussen [4] in order to explain drifts in the functioning of large risky organizations. The model hypothesizes that these organizations originally define a set of rules and procedures intended to make sure that they will operate within safety borders (in terms of economic performance, acceptable workload, quality, etc.) allowing theme to reach their goals. However, over time, systems drift towards the violation of the rules that were built and implemented at the time of their creation.

For Rasmussen, the drift is generated by a spontaneous tendency towards increased system performance and more individual advantages (e.g. minimizing efforts). Protection barriers can be implemented: dangerous actions may be made impossible, rules and procedures can be defined, etc. However, pressures from reality will tend to make people get past these barriers or transform them. The management will try to reach an increased performance at less cost, with less means, with equipment that is failing, absent or obsolete, with a less numerous or less trained personnel. Practices of operators also tend to migrate in order to cope with management transgressions.
The drift towards violations occurs little by little. Successive decisions, from multiple actors at different hierarchical levels (designers, administration, industrial partners, sub-contractors) are taken. Each decision is locally rational at the time when it is taken. But their succession leads to a gradual deterioration of the functioning of the organization. The consequence is an "illegalnormal" organizational functioning.

The situation we have studied can be analyzed through Rasmussen's model. Cuts of personnel, attempts to optimize performance, the increase in the number of tasks to be accomplished can be seen as gradual drifts. The management then implements new rules in order to fulfill performance objectives. Employees see these rules as violations of the initial contract, view them as a deterioration of the trade and react in different ways, sometimes by creating clandestine rules (as in example 2).

\section{Conclusion}

To us, a fundamental goal of ergonomics is the design of quality work. "Quality work" refers both to job quality (i.e. work as it is experienced by the worker: the work - or the job - one has) and product quality (i.e. the quality of the end result of work: the product of work). These two dimensions are correlated. Workers may be (and too often are) placed in such conditions that they feel that their production is below their own standards, because they lack time, appropriate equipment, proper training, support. When work organization sets obstacles to the production of quality, one has feeling of poor job quality.

Setting the issue in this way allows one to escape a frequent dead end in ergonomics, where performance issues are disconnected from health issues. The two issues are intertwined. Who wants to perform poorly? No one. Workers wish to perform well. Working conditions that do not allow one to fulfill their own criteria of work quality are a source of frustration and ill-being. Being able to perform well is thus a dimension of health.

Of course, this leads to another question: is quality from the worker's point of view the same as quality as seen by the organization? The answer is often no. It is so in the reported study. It is the job of the ergonomist to make organizations aware of this difference in points of view and to try and reduce it by changing work conditions. 


\section{References}

[1] Anact (2007) Special issue of Travail et Changement "Améliorer la qualité de vie au travail : des pistes pour agir”. May/June 2007.

[2] Boltanski, L et Thévenot, L. (1991) De la justification. Paris : Gallimard.

[3] (2010) Quality in work - Thematic review. http://ec.europa.eu/social/keyDocuments.jsp?ty $\mathrm{pe}=0 \&$ policyArea $=81 \&$ subCategory $=115 \& \mathrm{cou}$ ntry $=0 \& y e a r=0 \& a d v S e a r c h K e y=$ emcoreport $\&$ mode $=$ advancedSubmit\&langId $=$ en

[4] Rasmussen, J. (1997). Risk management in a dynamic society: a modelling problem. Safety Science, 27 (2/3), 183-213.

[5] Stiglitz, J.E., Sen, A. \& Fitoussi J.-P. (2008) Report by the Commission on the measurement of economic performance and social progress. www.stiglitz-sen-

fitoussi.fr/documents/rapport_anglais.pdf 